\title{
Long-Term Exposure of Rat Pancreatic Islets to Fatty Acids Inhibits Glucose- induced Insulin Secretion and Biosynthesis through a Glucose Fatty Acid Cycle
}

Yun-Ping Zhou and Valdemar E. Grill

Department of Endocrinology, Karolinska Hospital, Karolinska Institute, S-104 01 Stockholm, Sweden

\begin{abstract}
We tested effects of long-term exposure of pancreatic islets to free fatty acids (FFA) in vitro on B cell function. Islets isolated from male Sprague-Dawley rats were exposed to palmitate (0.125 or 0.25 mM), oleate (0.125 $\mathrm{mM})$, or octanoate (2.0 $\mathrm{mM}$ ) during culture. Insulin responses were subsequently tested in the absence of FFA. After a 48-h exposure to FFA, insulin secretion during basal glucose $(3.3 \mathrm{mM})$ was severalfold increased. However, during stimulation with $27 \mathrm{mM}$ glucose, secretion was inhibited by $30-50 \%$ and proinsulin biosynthesis by $30-40 \%$. Total protein synthesis was similarly affected. Conversely, previous palmitate did not impair $\alpha$-ketoisocaproic acid ( $5 \mathrm{mM}$ )-induced insulin release. Induction and reversibility of the inhibitory effect on glucose-induced insulin secretion required between 6 and $24 \mathrm{~h}$. Addition of the carnitine palmitoyltransferase I inhibitor etomoxir ( $1 \mu \mathrm{M})$ partially reversed (by $>\mathbf{5 0} \%$ ) FFA-associated decrease in secretory as well as proinsulin biosynthetic responses to $27 \mathrm{mM}$ glucose. The inhibitory effect of previous palmitate was similar when co-culture was performed with $5.5,11$, or $27 \mathrm{mM}$ glucose. Exposure to palmitate or oleate reduced the production of ${ }^{14} \mathrm{CO}_{2}$ from $\mathrm{D}-\left[\mathrm{U}-{ }^{14} \mathrm{C}\right] \mathrm{glucose}$, and of ${ }^{14} \mathrm{CO}_{2}$ from $\mathrm{D}-\left[3,4-{ }^{14} \mathrm{C}\right]-$ glucose, both effects being reversed by etomoxir. Conclusions: long-term exposure to FFA inhibits glucose-induced insulin secretion and biosynthesis probably through a glucose fatty acid cycle. (J. Clin. Invest. 1994. 93:870-876.) Key words: B cell insensitivity $\bullet$ fatty acids $\bullet$ insulin secretion $\bullet$ non-insulin-dependent diabetes mellitus $\bullet$ pancreatic islet
\end{abstract}

\section{Introduction}

The importance of FFA in the regulation of insulin secretion has not been thoroughly assessed. During nonstimulatory conditions, endogenous triacylglycerols are important fuels for intermediary metabolism of pancreatic islets (1). However, effects on insulin secretion are less impressive. Although FFA have been shown in vivo and in vitro to stimulate insulin secretion $(2,3)$, such stimulation is usually moderate, suggesting that FFA do not play a major role in regulation of insulin secretion.

Theoretically, elevated FFA, such as occur during starvation and diabetes, could influence insulin secretion in a major

Address correspondence to Dr. Valdemar Grill, Department of Endocrinology, Karolinska Hospital, Box 60500, S-104 01 Stockholm, Sweden.

Received for publication 30 July 1993 and in revised form 29 September 1993.

J. Clin. Invest.

(C) The American Society for Clinical Investigation, Inc.

0021-9738/94/02/0870/07 \$2.00

Volume 93, February 1994, 870-876 way if a glucose-fatty acid cycle were operative in the B cell. The concept of such a cycle was proposed by Randle et al. (4) many years ago. It encompasses the notion that the relationship between glucose and fatty acid breakdown is reciprocal and not dependent. Accordingly, increased oxidation of fatty acids, such as occurs in fasting and diabetes, will inhibit the metabolism of glucose (by several mechanisms, see reference 5 for review). This relationship between fatty acid oxidation and glucose metabolism has been documented in tissues such as heart muscle and liver (5). However, the existence of a glucose fatty acid cycle has not been demonstrated in pancreatic islets. Rather, most previous studies have seemed to disprove its existence. Hence in short-term experiments fatty acid oxidation did not negatively affect glucose oxidation (6). Furthermore, in a detailed study on the effects of a carnitine palmitoyl transferase I(CPT I $)^{1}$ inhibitor, methyl-palmoxirate, this inhibitor of long-chain fatty acid oxidation failed to affect $\mathrm{D}-\left[\mathrm{U}-{ }^{14} \mathrm{C}\right]-$ glucose oxidation, and did not enhance but, instead, diminished glucose-induced insulin release (7). More recently the CPT I inhibitor 2-bromopalmitate was shown to enhance glucose-induced insulin secretion in a clonal $\beta$ cell line of HIT cells $(8)$. However, it is difficult to decide whether these results in insulinoma cells are applicable to normal B cells.

Previous studies utilized mostly short-term protocols to study the interactions between FFA and glucose. It seemed possible that long-term exposure to FFA could induce effects different from those exerted by short-term exposure. This hypothesis was tested by infusing a lipid solution, Intralipid, for varying durations into rats (9). Glucose-induced insulin secretion was measured subsequent to infusion using the perfused pancreas. The effects of Intralipid turned out to be biphasic in time. After $3 \mathrm{~h}$ of infusion, glucose-induced insulin secretion was enhanced whereas it was decreased after $24 \mathrm{~h}$ and even more so after $48 \mathrm{~h}$ of infusion. These results indicated that the long-term hyperlipidemia inhibited glucose-induced insulin secretion.

Hyperlipidemia induces insulin resistence $(10,11)$ as well as many changes in nutrient and hormonal levels, all of which could potentially affect B cell function. Although the infusion experiments provided some data suggesting that the effects observed were related to fatty acid oxidation (9), they did not provide definite evidence that the effects of hyperlipidemia were directly caused by elevated FFA. Furthermore, even if such were the case, the relevance to physiology would be in doubt since Intralipid contains a much higher proportion of unsaturated fatty acids than plasma, its major fatty acid component being linoleic acid (9), whereas the dominating FFA in plasma are oleic and palmitic acid. The first aim of the present study was therefore to directly test for time-dependent effects of different concentrations of palmitate and of oleate on glucose-

1. Abbreviations used in this paper: CPT I, carnitine palmitoyl transferase I; PDH, pyruvate dehydrogenase. 
induced insulin secretion. The second aim was to test for effects of FFA on the other major effect of glucose on the B cell, namely, stimulation of insulin biosynthesis. The third aim was to test for coupling of FFA effects on secretion with effects on islet metabolism.

\section{Methods}

Materials. Palmitate, oleate, and octanoate (sodium salts) were purchased from Sigma Chemical Co. (St. Louis, MO). Sodium 2-[b-(4chlorophenoxy)-hexyl] oxirane-2-carboxylate (B-827-33, etomoxir) was from ASAT AG (Zug, Switzerland). L- $\left[4,5-{ }^{3} \mathrm{H}\right]$ leucine (sp act 62 $\mathrm{Ci} / \mathrm{mmol}$ ) was from Amersham International (Amersham, Bucks, UK). Undiluted guinea pig anti-porcine insulin serum was from ICN ImmunoBiologicals (Lisle, IL). Protein A-Sepharose CL-4B was from Pharmacia (Uppsala, Sweden). D-[U- $\left.{ }^{14} \mathrm{C}\right]$ glucose (sp act $320 \mathrm{mCi} /$ $\mathrm{mmol})$ and $\mathrm{D}-\left[3,4-{ }^{14} \mathrm{C}\right]$ glucose $(53.6 \mathrm{mCi} / \mathrm{mmol})$ were from New England Nuclear (Boston, MA). Hyamine hydroxide was from Packard Instrument Co. (Downers Grove, IL).

Animals. Male Sprague-Dawley rats were obtained from B \& K Universal, Stockholm, Sweden. They had free access to water and a standard pelleted diet (EWOS-ALAB Brook Stock Feed for rats and mice). The pellets contained on a weight basis $51.5 \%$ carbohydrate, $22 \%$ protein, and $5 \%$ fat. They were exposed to a $12-\mathrm{h} / 12$-h light (0600-1800)/dark cycle. At the time of experiments they weighed between 200 and $300 \mathrm{~g}$. The experimental protocols were approved by the Stockholm Ethical Committee for Research on Animals.

Isolation and culture of islets. Animals were killed by decapitation and pancreatic islets of Langerhans isolated as previously described (12), using digestion with collagenase obtained from Clostridium histolyticum (Boehringer Mannheim Gmb H, Mannheim, FRG). Digestion and sedimentation of islets were carried out in Hanks' solution containing $5.5 \mathrm{mM}$ glucose (Statens Bakteriologiska Laboratorium, Stockholm). Islets were then handpicked under a stereomicroscope and transferred to Petri dishes (Steriline, Teddington, UK) containing culture medium RPMI 1640 (Flow Laboratories, Erwing, UK) supplemented with $100 \mathrm{U} / \mathrm{ml}$ benzylpenicillin, $0.1 \mathrm{mg} / \mathrm{ml}$ streptomycin, 2 $\mathrm{mM}$ L-glutamine, and $10 \%$ ( $\mathrm{vol} / \mathrm{vol}$ ) heat-inactivated fetal calf serum (Sigma Chemical Co.). The concentration of glucose in culture media was $11.0 \mathrm{mM}$ when not otherwise indicated. Islets were cultured freefloating at $37^{\circ} \mathrm{C}$, with an atmosphere of $5 \% \mathrm{CO}_{2} / 95 \%$ air. The time period of culture was $48 \mathrm{~h}$ except in time course studies of induction and reversibility.

Table I. Effect of Ethanol and Etomoxir on Glucose-induced Insulin Release and Insulin Content of Rat Islets Maintained in Tissue Culture

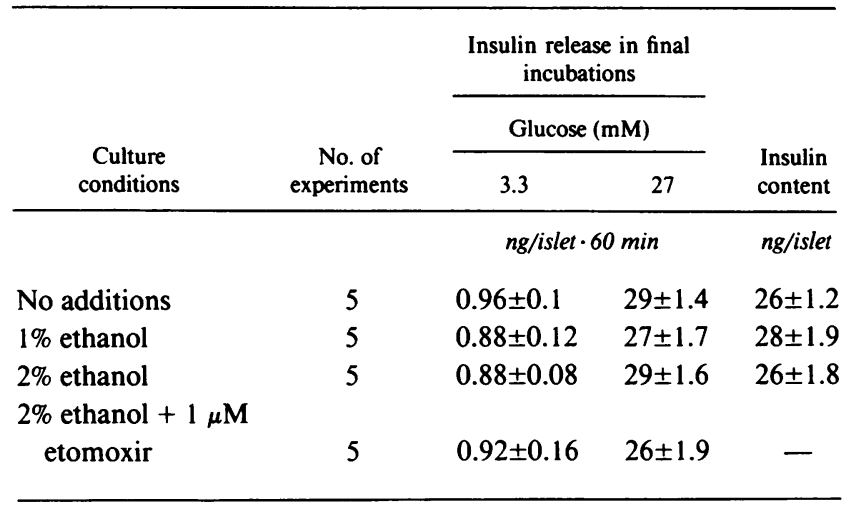

Islets were cultured for $48 \mathrm{~h}$ in RPMI 1640 with $11 \mathrm{mM}$ glucose, containing ethanol and etomoxir at the concentrations listed; insulin release was determined in 60 -min final incubations. No significant differences were found between experimental conditions.
Fatty acids (sodium salts) were dissolved in $95 \%$ ethanol before being added to culture media. The final concentration of ethanol in medium was $1 \%$ or $2 \%(\mathrm{vol} / \mathrm{vol})$ at the concentrations of FFA used in this study. Neither of the concentrations used during culture affected the subsequently tested insulin release nor islet insulin content (Table I). Control conditions with $1 \%$ or $2 \%$ ethanol during culture were included in each experiment.

Batch-type incubations of islets. After $48 \mathrm{~h}$ of culture in RPMI 1640 , islets were always preincubated for $30 \mathrm{~min}$ in KRB medium (13) with the following composition: $\mathrm{Na}^{+} 143.5 \mathrm{mM}, \mathrm{K}^{+} 5.8 \mathrm{mM}, \mathrm{Ca}^{2+} 2.5$ $\mathrm{mM}, \mathrm{Mg}^{2+} 1.2 \mathrm{mM}, \mathrm{Cl}^{-} 124.1 \mathrm{mM}, \mathrm{PO}_{4}^{3-} 1.2 \mathrm{mM}, \mathrm{SO}_{4}^{2+} 1.2 \mathrm{mM}$, $\mathrm{CO}_{3}^{2-} 25 \mathrm{mM}, \mathrm{pH} 7.4$, and supplemented with $10 \mathrm{mM}$ Hepes, $2 \mathrm{~g} /$ liter BSA (fraction IV, Sigma Chemical Co.), and $3.3 \mathrm{mM}$ glucose. Except for variations in glucose, this buffer was used throughout the study.

For insulin secretion studies, islets were selected after preincubation in batches of three islets in $200 \mu \mathrm{l}$ of KRB containing either 3.3 or $27 \mathrm{mM}$ glucose. Islets were incubated at $37^{\circ} \mathrm{C}$ for $60 \mathrm{~min}$. Triplicates or quadruplicates were run for each experimental condition. Incubations were carried out in a water bath with continuous shaking and in an atmosphere of $95 \% \mathrm{O}_{2} / 5 \% \mathrm{CO}_{2}$. At the end of incubations, aliquots of the incubation media were removed for insulin assay. Islets which, in final incubations, were exposed to $3.3 \mathrm{mM}$ glucose were retrieved for later determination of islet insulin content.

Proinsulin and total protein biosynthesis. For the study of proinsulin-insulin and total protein biosynthesis, groups of 10 islets were incubated as duplicates in polystyrene RIA tubes containing $100 \mu \mathrm{l}$ of KRB medium supplemented with $50 \mu \mathrm{Ci} / \mathrm{ml} \mathrm{L}-\left[4,5-{ }^{3} \mathrm{H}\right]$-leucine and 3.3 or $27 \mathrm{mM}$ glucose at $\mathrm{pH} 7.4$ for $2 \mathrm{~h}$ at $37^{\circ} \mathrm{C}$ (without shaking) in $95 \%$ $\mathrm{O}_{2} / 5 \% \mathrm{CO}_{2}$. After incubations, the medium containing radioactive leucine were carefully removed by suction. The islets were then washed twice with Hanks' solution containing nonradioactive leucine (10 $\mathrm{mM}$ ). The washed islets were sonicated in $200 \mu \mathrm{l}$ of redistilled water $(10 \times 2$ s., model B-12 sonifier, setting 4; Branson Ultrasonics Corp., Danbury, CT). The sonicates were then centrifuged $(10,000 \mathrm{~g}, 10 \mathrm{~min})$ at $4^{\circ} \mathrm{C}$ and the supernatants were used for subsequent analysis.

Proinsulin-insulin biosynthesis was measured by immunoprecipitation with undiluted antiinsulin serum (in excessive amount), and separation of immune complexes with protein A-Sepharose CL-4B as described (14). Total protein synthesis was determined by measurements of the radioactivity in the $10 \%$ TCA-precipitable fraction of the homogenate.

Glucose oxidation. The production of ${ }^{14} \mathrm{CO}_{2}$ from $\mathrm{D}-\left[\mathrm{U}-{ }^{14} \mathrm{C}\right]-$ glucose was measured basically as previously described (15). Briefly, duplicate groups of 10 islets each were placed in wells (central well, Kontes Co., Vineland, NJ) containing $100 \mu$ l of KRB medium supplemented with trace amounts of $\mathrm{D}-\left[\mathrm{U}-{ }^{14} \mathrm{C}\right]$ glucose plus nonradioactive glucose to a final concentration of either 3.3 or $27 \mathrm{mM}$. The wells were suspended in $20-\mathrm{ml}$ scintillation vials, which were gassed with $\mathrm{O}_{2} / \mathrm{CO}_{2}$ (95:5) and capped airtight with rubber membranes. The vials were shaken continuously for $90 \mathrm{~min}$ at $37^{\circ} \mathrm{C}$ in a water bath. Islet metabolism was stopped by an injection of $100 \mu \mathrm{l}$ of $0.2 \mathrm{M} \mathrm{HCl}$ into the wells. This was immediately followed by injection of $250 \mu \mathrm{l}$ of hyamine hydroxide into the outer vial. After a further incubation for $2 \mathrm{~h}$ at $37^{\circ} \mathrm{C}$ to allow the liberated $\mathrm{CO}_{2}$ to be trapped by the hyamine, $5 \mathrm{ml}$ of scintillation fluid was added to each vial and the radioactivity was counted in a Packard Instruments Tricarb model 1900 TR scintillation analyzer. Blank incubations were treated identically. Oxidation of glucose was calculated as picomoles of glucose converted to $\left[{ }^{14} \mathrm{C}\right] \mathrm{CO}_{2}$ per 10 islets/ $90 \mathrm{~min}$.

The procedure used to measure the generation of ${ }^{14} \mathrm{CO}_{2}$ from $\mathrm{D}$ $\left[3,4-{ }^{14} \mathrm{C}\right]$ glucose was identical to that for $\mathrm{D}-\left[\mathrm{U}_{-}{ }^{14} \mathrm{C}\right]$ glucose oxidation described above except for using $50 \mu \mathrm{l}$ of $\mathrm{KRB}$, which contained 0.4$1.0 \mu \mathrm{Ci} / \mathrm{ml} \mathrm{D}-\left[3,4-{ }^{14} \mathrm{C}\right]$ glucose, and $120 \mathrm{~min}$ for incubation as previously reported (16).

Measurements of insulin release and islet insulin content. Insulin was measured by RIA using rat insulin as standard, monoiodinated porcine insulin as tracer, and charcoal premixed with Dextran $T 70$ (Pharmacia, Uppsala) to separate antibody bound insulin from free 
insulin (17). Insulin antibodies had been raised in our laboratory against porcine insulin.

For the determination of islet insulin contents, three islets each were put into $200 \mu$ l of acid-ethanol $(0.18 \mathrm{M} \mathrm{HCl}$ in $95 \%$ ethanol); insulin was extracted overnight at $4^{\circ} \mathrm{C}$ after sonification as previously described (18).

Presentation of results. All results are expressed as the mean \pm SE. Significance testing was performed using two-tailed Student's $t$ test for unpaired data and one-way ANOVA with the Student-NewmanKeuls' test.

\section{Results}

Effects of a 48-h exposure to FFA on glucose-induced insulin secretion and insulin content. The effects of $48 \mathrm{~h}$ of culture with palmitate, oleate, or octanoate are shown in Table II. Previous exposure to all three fatty acids increased fourfold or more insulin release during subsequent incubations with $3.3 \mathrm{mM}$ glucose, i.e., a nonstimulating concentration of the hexose. Contrariwise, all these three fatty acids inhibited insulin release during stimulation with $27 \mathrm{mM}$ glucose. With palmitate, inhibition was more marked after $0.25 \mathrm{mM}$ than after $0.125 \mathrm{mM}$ of this fatty acid. At equimolar concentrations of $0.125 \mathrm{mM}$, the inhibitory effect after previous palmitate was $30 \%$, and after previous oleate $42 \%$. The incremental response to $27 \mathrm{mM}$ glucose was inhibited by $82 \%$ after palmitate and by $86 \%$ after oleate. All three fatty acids reduced islet insulin contents ( Table II). At equal concentrations $(0.125 \mathrm{mM})$, the reduction was $23 \%$ after palmitate and $40 \%$ after oleate.

Table II. Effects of 48 h of Exposure to Fatty Acids with or without Etomoxir on Insulin Release and Islet Insulin Content

\begin{tabular}{|c|c|c|c|c|}
\hline \multirow{3}{*}{$\begin{array}{l}\text { Culture } \\
\text { conditions }\end{array}$} & \multirow{3}{*}{$\begin{array}{c}\text { No. of } \\
\text { experiments }\end{array}$} & \multirow{2}{*}{\multicolumn{2}{|c|}{$\begin{array}{c}\begin{array}{c}\text { Insulin release in final } \\
\text { incubations }\end{array} \\
\text { Glucose (mM) }\end{array}$}} & \multirow{3}{*}{$\begin{array}{l}\text { Insulin } \\
\text { content }\end{array}$} \\
\hline & & & & \\
\hline & & 3.3 & 27 & \\
\hline & & ng/islet & $60 \mathrm{~min}$ & $n g / i s l e t$ \\
\hline \multicolumn{5}{|l|}{ Control ( $1 \%$ ethanol } \\
\hline$+1 \mu \mathrm{M}$ etomoxir) & 5 & $1.1 \pm 0.1$ & $36 \pm 1.7$ & $28 \pm 1.8$ \\
\hline $0.25 \mathrm{mM}$ palmitate & 5 & $5.0 \pm 0.5^{*}$ & $19 \pm 1.5^{*}$ & $16 \pm 1.0^{*}$ \\
\hline \multicolumn{5}{|l|}{$0.25 \mathrm{mM}$ palmitate } \\
\hline$+1 \mu \mathrm{M}$ etomoxir & 5 & $4.4 \pm 0.7^{*}$ & $26 \pm 1.6^{* \pm}$ & $19 \pm 1.7^{8}$ \\
\hline $0.125 \mathrm{mM}$ oleate & 5 & $4.7 \pm 0.8^{*}$ & $21 \pm 1.6^{8}$ & $17 \pm 1.5^{*}$ \\
\hline \multicolumn{5}{|l|}{$0.125 \mathrm{mM}$ oleate } \\
\hline$+1 \mu \mathrm{M}$ etomoxir & 5 & $3.5 \pm 0.6^{*}$ & $29 \pm 2.0^{811}$ & $22 \pm 1.7^{\ddagger}$ \\
\hline \multicolumn{5}{|l|}{ Control ( $1 \%$ ethanol } \\
\hline$+1 \mu \mathrm{M}$ etomoxir & 3 & $1.3 \pm 0.1$ & $33 \pm 2.0$ & $27 \pm 2.4$ \\
\hline $0.125 \mathrm{mM}$ palmitate & 3 & $5.2 \pm 0.9^{*}$ & $24 \pm 1.5^{*}$ & $21 \pm 1.4^{1}$ \\
\hline \multicolumn{5}{|l|}{$0.125 \mathrm{mM}$ palmitate } \\
\hline$+1 \mu \mathrm{M}$ etomoxir & 3 & $4.7 \pm 0.7^{*}$ & $31 \pm 1.9^{\prime \prime}$ & $25 \pm 1.3^{\ddagger}$ \\
\hline Control ( $2 \%$ ethanol) & 5 & $1.7 \pm 0.2$ & $33 \pm 1.4$ & - \\
\hline Octanoate $2.0 \mathrm{mM}$ & 5 & $6.1 \pm 0.6^{*}$ & $13 \pm 1.5^{*}$ & $22 \pm 1.8^{\prime}$ \\
\hline \multicolumn{5}{|l|}{ Octanoate $2.0 \mathrm{mM}$} \\
\hline$+1 \mu \mathrm{M}$ etomoxir & 5 & $4.3 \pm 0.5^{*}$ & $15 \pm 1.1^{*}$ & $21 \pm 4.1^{\prime \prime}$ \\
\hline
\end{tabular}

Insulin release was measured in 60 -min final incubations after $48 \mathrm{~h}$ of culture followed by a 30 -min preincubation in KRB containing 3.3 $\mathrm{mM}$ glucose. Data are means \pm SE. $' P<0.05 ;{ }^{\circledR} P<0.01$; and ${ }^{*} P$ $<0.001$ compared with control. ${ }^{\ddagger} P<0.05$; $" P<0.01$ for the effect of etomoxir.

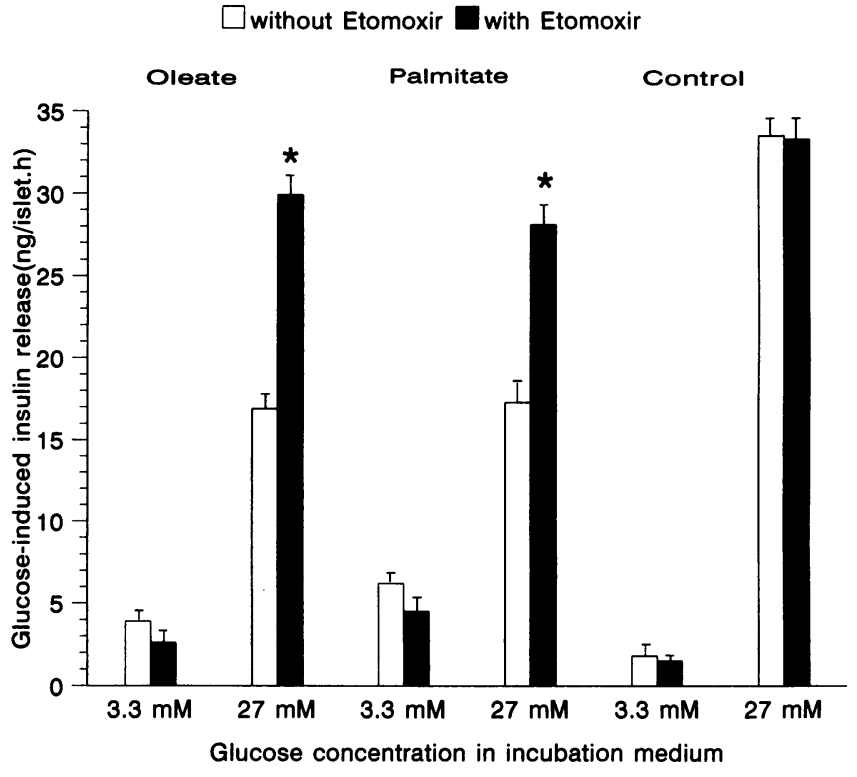

Figure 1. Effects of etomoxir $(1 \mu \mathrm{M})$ present after culture on FFAassociated impairment of insulin response to glucose. Islets cultured with palmitate or oleate (but not etomoxir) for $48 \mathrm{~h}$ were transferred to the KRB medium with or without $1 \mu \mathrm{M}$ etomoxir, and underwent preincubation ( $30 \mathrm{~min}$ ) and final incubation $(60 \mathrm{~min}$ ) to measure glucose-induced insulin release. Data are means \pm SE. of five or six experiments. ${ }^{*} P<0.01$ for effect of etomoxir. Control means islets cultured without palmitate.

Influence of etomoxir on FFA-induced changes of insulin secretion. Etomoxir, one of the mitochondrial CPT I inhibitors containing oxirane carboxylates $(19,20)$, was used to test whether inhibition of the $\beta$-oxidation of long-chain fatty acids, such as palmitate and oleate, could reverse their effects on insulin secretion (Table II). Addition of $1 \mu \mathrm{M}$ etomoxir to culture media did not per se influence basal or glucose-induced insulin secretion (Table I). Addition of etomoxir to culture media containing fatty acids did not significantly affect the fatty acidstimulated insulin secretion in the presence of $3.3 \mathrm{mM}$ glucose. Etomoxir during culture with palmitate or oleate partially (by $75 \%$ for $0.125 \mathrm{mM}$ palmitate, and by $48 \%$ for $0.125 \mathrm{mM}$ oleate) reversed the inhibitory effects of these fatty acids on insulin response to $27 \mathrm{mM}$ glucose.

Specificity of the etomoxir effect was tested by adding the CPT I inhibitor to culture media containing octanoate. The oxidation of this fatty acid is known not to involve the CPT enzyme (21). In our experiments, previous etomoxir together with octanoate failed to significantly affect the inhibitory effect on glucose-induced insulin secretion exerted by culture with this fatty acid (Table II).

Etomoxir partially reversed the reduction in islet insulin content brought about by palmitate or oleate. However, the reduction in islet insulin content brought about by octanoate was not affected.

In another series of experiments, etomoxir was added from preincubation and onward, but not during culture. Also in these experiments, etomoxir partially reversed FFA-associated impairment of $27 \mathrm{mM}$ glucose-induced insulin secretion (Fig. 1). Finally, exposure to etomoxir was tested from the beginning of the culture period up to the end of final incubations (five experiments). Also, this protocol resulted in near total reversibility by etomoxir. Thus secretion was $17 \pm 1.2 \mathrm{ng} /$ islet $\cdot h$ in the absence and $24 \pm 1.1 \mathrm{ng} /$ islet $\cdot h$ in the presence of 


\begin{tabular}{|c|c|c|c|c|c|c|}
\hline \multirow[b]{4}{*}{ Duration of culture } & \multicolumn{4}{|c|}{ Insulin release in final incubations } & & \\
\hline & \multicolumn{2}{|c|}{ Control (1\% eth) } & \multicolumn{2}{|c|}{ Previous palmitate } & & \\
\hline & \multicolumn{2}{|c|}{ Glucose (mM) } & \multicolumn{2}{|c|}{ Glucose (mM) } & \multicolumn{2}{|c|}{ Insulin content } \\
\hline & 3.3 & 27 & 3.3 & 27 & Control & Previous palmitate \\
\hline$h$ & \multicolumn{4}{|c|}{$\mathrm{ng} / \mathrm{islet} \cdot 60 \mathrm{~min}$} & \multicolumn{2}{|c|}{ ng/islet } \\
\hline 6 & $1.2 \pm 0.1$ & $40 \pm 1.5$ & $2.5 \pm 0.3^{*}$ & $38 \pm 2.1$ & $29 \pm 3.2$ & $19 \pm 3.3^{*}$ \\
\hline 24 & $1.3 \pm 0.1$ & $35 \pm 1.4^{\ddagger}$ & $3.1 \pm 0.4^{*}$ & $29 \pm 1.7^{\S}$ & $23 \pm 3.9$ & $16 \pm 2.9^{\S}$ \\
\hline 48 & $1.3 \pm 0.1$ & $28 \pm 2.5^{\prime \prime}$ & $2.1 \pm 0.2^{*}$ & $14 \pm 1.2^{*}$ & $23 \pm 3.1$ & $15 \pm 2.9^{\S}$ \\
\hline
\end{tabular}

Islets were cultured with or without $0.125 \mathrm{mM}$ palmitate for 6,24 , and $48 \mathrm{~h}$. Results are means $\pm \mathrm{SE}$ of five experiments. ${ }^{\S} P<0.01 ;{ }^{*} P<0.001$ when compared with control ( $1 \%$ ethanol). ${ }^{\ddagger} P<0.05$, " $P<0.01$ when compared with 6-h exposure group.

etomoxir for culture with $0.25 \mathrm{mM}$ palmitate; and $19 \pm 1.0 \mathrm{ng} /$ islet $\cdot h$ in the absence and $26 \pm 1.5 \mathrm{ng} /$ islet $\cdot h$ in the presence of etomoxir for culture with $0.125 \mathrm{mM}$ oleate, the normal control response being $26 \pm 1.9 \mathrm{ng} /$ islet $\cdot \mathrm{h}$.

Time course for induction and reversibility of palmitate-induced effects. Induction time for FFA effects on insulin secretion was studied by exposing islets to $0.125 \mathrm{mM}$ palmitate for 6,24 , or $48 \mathrm{~h}$. As can be seen from Table III, the basal insulin secretion at $3.3 \mathrm{mM}$ glucose was elevated near-maximally already after $6 \mathrm{~h}$ of palmitate exposure when compared with control conditions (culture at RPMI 1640 with $1 \%$ ethanol ). In contrast, the insulin response to $27 \mathrm{mM}$ glucose was significantly reduced only after $24 \mathrm{~h}$ exposure. A 48-h exposure was needed to induce a marked effect (lowering to $50 \%$ of the control).

Insulin contents in palmitate-exposed islets were reduced already after a $6-\mathrm{h}$ exposure (to $60 \%$ of the control). With longer exposure, the absolute values decreased further; however, due to some reduction with time of culture in insulin contents of control islets, there was no further drop in the ratio of insulin content between palmitate-exposed and control islets.

The same experiments which were used to evaluate induction were continued to assess also the time of reversibility. Islets which had been exposed to palmitate or ethanòl for $48 \mathrm{~h}$ (and not used for measurements of induction) were transferred to standard RPMI 1640 medium with $11.0 \mathrm{mM}$ glucose and 2 $\mathrm{mM}$ L-glutamine but without palmitate. After $6 \mathrm{~h}$ of recovery culture, the influence of palmitate exposure persisted both with regard to the increased basal and decreased stimulated insulin secretion (Fig. 2). However, after $24 \mathrm{~h}$, both basal and stimulated insulin secretion were restored to normal. Insulin contents in these islets also increased significantly (from $29 \pm 2.7$ $\mathrm{ng} /$ islet at $6 \mathrm{~h}$, to $38 \pm 55.4 \mu \mathrm{U} /$ islet at $24 \mathrm{~h}$ ); however, these contents were still lower than those of control condition ( $47 \pm 2.2 \mathrm{ng} /$ islet, $P<0.01$ ).

Effect of glucose concentration during culture on effects of palmitate. To evaluate the possible interaction between hyperglycemia and FFA on glucose-induced insulin release, the exposure of islets to $0.125 \mathrm{mM}$ palmitate were compared for three different glucose concentrations $(5.5,11.0$, and $27 \mathrm{mM})$ during culture. Increasing the glucose concentration from 5.5 to $11 \mathrm{mM}$ did not affect basal release at $3.3 \mathrm{mM}$ glucose in control culture. However, the increase in glucose during culture augmented the stimulatory effect of palmitate at $3.3 \mathrm{mM}$ glucose (Table IV). Increasing the glucose concentration to 27 $\mathrm{mM}$ led to 5.7 -fold higher release at $3.3 \mathrm{mM}$ glucose. Co-culture of palmitate with $27 \mathrm{mM}$ glucose did not further increase subsequent release at $3.3 \mathrm{mM}$ glucose. Hence culture at an intermediate glucose concentration enhanced, whereas culture at a high glucose concentration diminished the stimulatory effect of previous palmitate per se.

The inhibitory influence of palmitate, on the other hand, was not affected by increasing the glucose concentration during culture. Thus no difference was apparent in FFA-induced attenuation of $27 \mathrm{mM}$ glucose-induced insulin release whether the culture medium contained 5.5, 11, or $27 \mathrm{mM}$ glucose (Table IV). Also the magnitude of palmitate-induced decrease in insulin contents seemed unaffected by glucose concentration during culture, the decrease being additive to that brought about by culture with $27 \mathrm{mM}$ glucose alone.

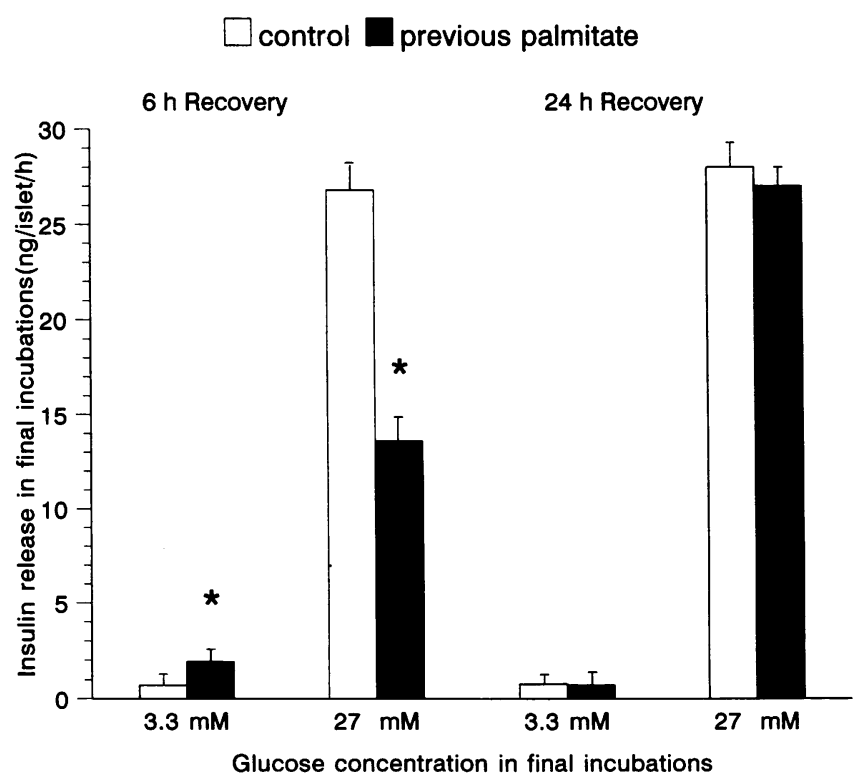

Figure 2. Reversibility of palmitate-induced impairment of insulin response to glucose in cultured rat islets. After $48 \mathrm{~h}$ of culture with $0.125 \mathrm{mM}$ palmitate, islets were transferred to standard RPMI 1640 medium (with $11 \mathrm{mM}$ glucose and $2 \mathrm{mM}$ glutamine) for an additional 6- or 24-h of recovery culture. Insulin release was subsequently measured in batch-type incubations in KRB with 3.3 or $27 \mathrm{mM}$ glucose. Results are means \pm SE. of five experiments. ${ }^{*} P<0.001$ when compared with control. 
Table IV. Effects of Glucose Concentration during Culture on Palmitate-induced Effects on Insulin Release and Insulin Contents

\begin{tabular}{|c|c|c|c|c|c|c|}
\hline \multirow{4}{*}{$\begin{array}{l}\text { Glucose in culture } \\
\text { medium }\end{array}$} & \multicolumn{4}{|c|}{ Insulin release in final incubations } & & \\
\hline & \multicolumn{2}{|c|}{ Control } & \multicolumn{2}{|c|}{ Previous palmitate } & & \\
\hline & \multicolumn{2}{|c|}{ Glucose $(\mathrm{mM})$} & \multicolumn{2}{|c|}{ Glucose (mM) } & \multicolumn{2}{|c|}{ Insulin content } \\
\hline & 3.3 & 27 & 3.3 & 27 & Control & Previous palmitate \\
\hline$m M$ & \multicolumn{4}{|c|}{$\mathrm{ng} / \mathrm{islets} \cdot 60 \mathrm{~min}$} & \multicolumn{2}{|c|}{ ng/islet } \\
\hline 5.5 & $1.1 \pm 0.1$ & $23 \pm 0.8$ & $3.9 \pm 0.5^{*}$ & $18 \pm 1.6^{\ddagger}$ & $31 \pm 1.9$ & $21 \pm 3.3^{\ddagger}$ \\
\hline 11.0 & $1.0 \pm 0.1$ & $24 \pm 0.6$ & $6.5 \pm 0.3^{*}$ & $20 \pm 1.0^{\ddagger}$ & $37 \pm 2.5$ & $18 \pm 1.3^{*}$ \\
\hline 27.0 & $6.4 \pm 0.5$ & $26 \pm 0.5$ & $7.0 \pm 0.4$ & $21 \pm 0.8^{*}$ & $25 \pm 2.5$ & $16 \pm 2.9^{\ddagger}$ \\
\hline
\end{tabular}

Islets were cultured in RPMI 1640 medium containing the three different concentrations of glucose, in the presence or absence of $0.125 \mathrm{mM}$ palmitate for $48 \mathrm{~h}$. Insulin responses to 3.3 or $27 \mathrm{mM}$ glucose were measured in the 60 -min final batch-type incubations. Data are means $\pm S E$ of four experiments. ${ }^{*} P<0.001$ and ${ }^{\ddagger} P<0.05$ when compared with control.

Effect of palmitate on $\alpha$-ketoisocaproic acid-induced insulin release. To examine the specificity of inhibition by fatty acids of glucose-induced insulin release, we tested the effects of palmitate during culture on subsequent release induced by $5 \mathrm{mM}$ $\alpha$-ketoisocaproic acid. In contrast to its inhibitory effect on glucose-induced insulin release, previous $0.125 \mathrm{mM}$ palmitate failed to inhibit and even slightly increased $\alpha$-ketoisocaproic acid-induced insulin secretion. Thus release after previous palmitate was $16 \pm 1.2$ vs. $13 \pm 0.75 \mathrm{ng} /$ islet $\cdot 60$ min during control conditions, $P<0.05$ ).

Effects of FFA on proinsulin and total protein biosynthesis in islets. Effects of $48 \mathrm{~h}$ of exposure to $0.125 \mathrm{mM}$ palmitate or oleate on islet biosynthesis are shown in Table V. At $3.3 \mathrm{mM}$ glucose neither palmitate nor oleate influenced incorporation of $\left[{ }^{3} \mathrm{H}\right]$ leucine into proinsulin-insulin. However, incorporation at $27 \mathrm{mM}$ glucose was inhibited by both fatty acids. Inhibition of the absolute rate of biosynthesis amounted to $40 \%$ for palmitate and $28 \%$ for oleate. Also the effects of glucose on total protein synthesis in the presence of $27 \mathrm{mM}$ glucose were inhibited by palmitate and oleate. The inhibitory effects on total protein synthesis were no less than on proinsulin biosynthesis. Hence the fatty acids did not change the relative contribution of proinsulin synthesis to total protein synthesis.

Addition of $1 \mu \mathrm{M}$ etomoxir to culture media significantly reversed the inhibitory effects of palmitate and oleate on glu- cose-stimulated proinsulin biosynthesis. There was a tendency, albeit nonsignificant, for reversal of inhibition of total protein synthesis (Table V).

Effects of FFA on glucose oxidation. The rate of $\mathrm{D}-\left[\mathrm{U}-{ }^{14} \mathrm{C}\right]-$ glucose oxidation at $3.3 \mathrm{mM}$ of the hexose was not influenced by culture with palmitate or oleate (Table VI). However, oxidation in the presence of $27 \mathrm{mM}$ glucose was inhibited by $24 \%$ and $32 \%$ in islets cultured in medium containing respectively palmitate or oleate. The co-presence of $1 \mu \mathrm{M}$ Etomoxir with palmitate or oleate in culture media restored the impaired oxidation rate to normal or near normal.

The rate of $\mathrm{D}-\left[3,4-{ }^{14} \mathrm{C}\right]$ glucose was also studied in order to assess an influence of FFA on the decarboxylation of pyruvate. The production of ${ }^{14} \mathrm{CO}_{2}$ was decreased by culture with palmitate or oleate. The inhibitory effect amounted to $35 \%$ after palmitate and $39 \%$ after oleate. This inhibition was fully reversible by etomoxir.

\section{Discussion}

Our results show that exposure to fatty acids in vitro leads to profound inhibition of glucose-induced insulin secretion. To our knowledge, such an effect has not previously been documented in vitro. The absence of an inhibitory effect in other studies is explainable by the fact that short-term effects were

Table V. Effects of FFA and Etomoxir on Proinsulin and Total Protein Biosynthesis

\begin{tabular}{|c|c|c|c|c|c|c|}
\hline \multirow[b]{3}{*}{ Culture conditions } & \multicolumn{2}{|c|}{ Proinsulin synthesis (PI) } & \multicolumn{2}{|c|}{ Total protein synthesis (TP) } & \multicolumn{2}{|c|}{ Percent PI of TP } \\
\hline & \multicolumn{2}{|c|}{ Glucose (mM) } & \multicolumn{2}{|c|}{ Glucose (mM) } & \multicolumn{2}{|c|}{ Glucose (mM) } \\
\hline & 3.3 & 27 & 3.3 & 27 & 3.3 & 27 \\
\hline & \multicolumn{4}{|c|}{$10^{3} \mathrm{dpm} / \mathrm{islet} \cdot 2 \mathrm{~h}$} & \multicolumn{2}{|c|}{$\%$} \\
\hline No addition & $3.38 \pm 0.4$ & $6.45 \pm 0.51$ & $9.26 \pm 1.02$ & $16.5 \pm 1.72$ & $33.4 \pm 2.0$ & $39.8 \pm 2.0$ \\
\hline $1 \%$ ethanol & $2.54 \pm 0.26$ & $5.71 \pm 0.31$ & $8.74 \pm 0.94$ & $17.6 \pm 0.73$ & $29.3 \pm 1.6$ & $32.6 \pm 1.7$ \\
\hline $1 \%$ ethanol $+1 \mu \mathrm{M}$ etomoxir & $2.52 \pm 0.27$ & $4.98 \pm 0.40$ & $8.15 \pm 0.63$ & $14.2 \pm 1.25$ & $30.6 \pm 1.1$ & $34.9 \pm 0.7$ \\
\hline Palmitate $(0.125 \mathrm{mM})$ & $2.41 \pm 0.21$ & $3.41 \pm 0.34^{*}$ & $7.98 \pm 0.67$ & $9.77 \pm 0.71^{*}$ & $30.0 \pm 1.0$ & $34.7 \pm 2.3$ \\
\hline Palmitate + etomoxir & $2.70 \pm 0.19$ & $4.99 \pm 0.65^{\ddagger}$ & $7.73 \pm 0.56$ & $13.8 \pm 1.97$ & $35.5 \pm 2.1$ & $36.0 \pm 1.9$ \\
\hline Oleate $(0.125 \mathrm{mM})$ & $3.14 \pm 0.11$ & $4.16 \pm 0.19^{*}$ & $9.24 \pm 0.71$ & $12.0 \pm 0.78^{*}$ & $35.1 \pm 1.9$ & $35.2 \pm 2.2$ \\
\hline Oleate + etomoxir & $3.44 \pm 0.25$ & $5.46 \pm 0.47^{\ddagger}$ & $9.62 \pm 0.54$ & $14.8 \pm 1.40$ & $36.1 \pm 1.7$ & $36.2 \pm 0.7$ \\
\hline
\end{tabular}

Islets were exposed to fatty acids in culture for $48 \mathrm{~h}$, in the presence or absence of $1 \mu \mathrm{M}$ etomoxir. Afterward, proinsulin biosynthesis was determined by measuring the incorporation of $\mathrm{L}-\left[3,4-{ }^{3} \mathrm{H}\right]$ leucine, and the total protein synthesis was determined by counting the $10 \%$ TCA-precipitable fraction of radioactivity. Values are means $\pm \mathrm{SE}$ of four experiments. ${ }^{*} P<0.01$ vs. $1 \%$ ethanol; ${ }^{\ddagger} P<0.05$ vs. those with FFA only. 


\begin{tabular}{|c|c|c|c|c|}
\hline \multirow[b]{4}{*}{ Culture conditions } & \multicolumn{4}{|c|}{ Glucose oxidation } \\
\hline & \multicolumn{2}{|c|}{$D-\left[U-{ }^{14} \mathrm{C}\right] g l u \operatorname{cose}(n=5)$} & \multicolumn{2}{|c|}{ D- $\left[3,4^{-14} \mathrm{C}\right] g$ lucose $(n=4)$} \\
\hline & \multicolumn{4}{|c|}{ Glucose in incubation medium (mM) } \\
\hline & 3.3 & 27 & 3.3 & 27 \\
\hline & \multicolumn{4}{|c|}{$\mathrm{pmol} / 10$ islets $\cdot 90 \mathrm{~min}$} \\
\hline No additions (RPMI $+11 \mathrm{mM}$ glucose) & $159 \pm 20.4$ & $828 \pm 78.9$ & - & - \\
\hline $1 \%$ ethanol $+1 \mu \mathrm{M}$ etomoxir & $158 \pm 10.7$ & $866 \pm 68.4$ & $92 \pm 12$ & $391 \pm 29$ \\
\hline Palmitate $0.125 \mathrm{mM}$ & $173 \pm 13.4$ & $660 \pm 54.1^{*}$ & $102 \pm 4.9$ & $260 \pm 15^{\ddagger}$ \\
\hline Palmitate $0.125 \mathrm{mM}$ + etomoxir & $161 \pm 11.3$ & $890 \pm 88.5^{\S}$ & $109 \pm 14$ & $383 \pm 32^{\prime \prime}$ \\
\hline Oleate $0.125 \mathrm{mM}$ & $151 \pm 13.5$ & $592 \pm 53.4^{\ddagger}$ & $98 \pm 9.2$ & $239 \pm 33^{\ddagger}$ \\
\hline Oleate $0.125 \mathrm{mM}+$ etomoxir & $156 \pm 15.3$ & $807 \pm 67.1^{\S}$ & $98 \pm 12$ & $358 \pm 34^{\prime \prime}$ \\
\hline
\end{tabular}

Data are means \pm SEM of four separate experiments. ${ }^{*} P<0.05,{ }^{\ddagger} P<0.01$ when compared with control ( $1 \%$ ethanol plus $1 \mu \mathrm{M}$ etomoxir); ${ }^{\S} P$ $<0.05$, " $P<0.01$ when compared with those exposed to FFA only.

usually investigated $(2,3,22,23)$. Our study shows that induction of inhibition by FFA requires a long induction time, i.e., between 6 and $24 \mathrm{~h}$.

Several observations indicate that the inhibitory effect of long-term FFA is not due to unspecific damage of B cell function. First, the effect was reversible upon removal of FFA on a time scale comparable with that for induction. Second, responses to another nutrient secretagogue, $\alpha$-ketoisocaproic acid, were not inhibited. Third, an effect of FFA on glucose-induced insulin release was rapidly reversible by etomoxir (see further below).

Our findings strongly indicate coupling between fatty acid oxidation and the time-dependent inhibition of glucose-induced insulin secretion. Etomoxir, which is a CPT I inhibitor $(19,20)$, thus partially reversed the inhibitory effect of palmitate or oleate. The specificity of the etomoxir effect is highlighted by failure of the drug to significantly reverse the inhibition of glucose-induced insulin secretion caused by previous octanoate. By virtue of being a medium chain fatty acid, octanoate is known to enter mitochondria and to be metabolized without involvement of the CPT I enzyme (21).

We observed that etomoxir can reverse inhibition of glucose-induced insulin secretion not only when added during culture but also when added solely after culture in the absence of exogenous FFA. The efficiency of etomoxir when present solely after culture indicates the importance of breakdown of islet endogenous triacylglycerols for the inhibitory effect of FFA. The same mechanism (inhibition of utilization of FFA derived from endogenous triacylglycerols) should underlie at least in part the effects of etomoxir after its presence during culture. Thus etomoxir forms covalent bonds with the CPT I enzyme (19-21) causing irreversible inhibition of this enzyme. This leads to a prolonged effect of etomoxir which extends to the test period following culture. The failure of etomoxir to reverse inhibition by previous octanoate is probably due to the buildup of triacylglycerols containing residues of octanoic acid during exposure to octanoate. Subsequent lipolysis would then yield predominantly such residues which can be transported into mitochondria for $\beta$-oxidation also in the presence of etomoxir.

The present study demonstrates an influence of long-term FFA not only on glucose-induced insulin secretion but, to our knowledge for the first time, an effect also on glucose-induced proinsulin and total protein biosynthesis in islets. The results with etomoxir indicate the importance of fatty acid oxidation also on this modality of glucose regulation. The findings on biosynthesis are compatible with the observed decrease in islet insulin content that was universally observed after FFA. Such decrease could also partially be explained by the increased insulin secretion which occurred after FFA exposure but before measurements of islet insulin contents.

Our data on glucose oxidation indicate that the inhibitory effects of FFA on glucose-induced insulin secretion and biosynthesis are exerted at the level of glucose oxidation. In previous studies glucose oxidation has repeatedly been shown to be linked to the insulin-releasing potency of the hexose $(24,25)$. In our experiments a 48-h culture with palmitate or oleate significantly decreased oxidation of $\mathrm{D}-\left[\mathrm{U}-{ }^{14} \mathrm{C}\right]$ glucose, and this inhibition was reversed by etomoxir. Evidence obtained from other tissues indicate that inhibition of glucose metabolism by FFA is mainly exerted on the pyruvate dehydrogenase (PDH) enzyme complex (5). The failure of previous FFA to affect the insulin response to $\alpha$-ketoisocaproic acid is compatible with such notion since this nutrient is oxidized through the citric acid cycle without involvement of PDH. Also we find that production of ${ }^{14} \mathrm{CO}_{2}$ from $\mathrm{D}-\left[3,4-{ }^{14} \mathrm{C}\right]$ glucose, which reflects the decarboxylation of pyruvate due to $\mathrm{PDH}$ activity, is depressed after long-term exposure to FFA.

In addition to the inhibitory effects of glucose-induced insulin secretion, FFA also exerted stimulatory effects on secretion. In the short-term perspective, such effects are well documented in previous studies $(2,3,22,23)$. Such effects may be linked to mitochondrial oxidation and/or the breakdown in the cytoplasm of long chain acyl-CoA esters to second messengers such as diacylglycerol (8). The present study clearly shows that, in contrast to the inhibitory effects of FFA, a long induction time was not necessary for a stimulatory effect of previous FFA. However, the time of reversibility did not differ between the stimulatory and inhibitory effects. The similarity in reversibility could plausibly be due to increased endogenous triacylglycerols being present for an extended period of time after culture with FFA, such stores delivering the substrate necessary for the previously established influences of FFA.

It is interesting to note that variations in glucose concentra- 
tions during culture with FFA produced quite different results on secretion when the concentration of glucose in final incubations was 27 as compared to $3.3 \mathrm{mM}$ glucose. The inhibitory effect of FFA on the subsequent response to $27 \mathrm{mM}$ glucose was thus similar regardless of whether the culture medium contained 3.3, 11, or $27 \mathrm{mM}$ glucose. Conversely, the enhancement by previous FFA of secretion at basal glucose was obliterated by increasing the glucose concentration during culture from 11 to $27 \mathrm{mM}$. Of possible relevance to the latter effect are previous findings, showing (in short-term experiments) that a high glucose concentration decreases the oxidation of palmitate $(1,6,26)$.

What is the relevance of our results for in vivo conditions? The type of FFA and concentrations used bear on this question. The fact that our results were achieved using those fatty acids (palmitate and oleate) which are most common in rat and man supports relevance for in vivo conditions. Concerning concentrations, those of palmitate or oleate were about $25 \%$ of FFA in rat plasma (9); however, the non-protein-bound fraction was probably elevated since serum proteins including albumin, were only present in the $10 \%$ concentration of the fetal calf serum. The possible impact of these differences between culture medium and plasma on FFA effects remains to be evaluated.

Other observations support the notion that the long-term effects of FFA that we observed in vitro are operative in the B cell during physiological and pathophysiological conditions. First, and most important, several of the present findings are similar to our results in lipid-infused rats (9). Also in the previous study, an induction period of more than $6 \mathrm{~h}$ was necessary to induce inhibition of glucose-induced insulin secretion. As in the present study, such inhibition was also specific for glucose-induced insulin secretion. Second, the effects of a high fat diet resemble our results. Such a diet in diabetic mice leads to a decrease of glucose-induced insulin secretion, biosynthesis, and oxidation (27). Also, in suckling neonate rats (receiving a high fat nutrition), inhibition of FFA oxidation was shown to enhance glucose-induced insulin secretion (28). Third, in the present study, the inhibitory effect of FFA was present also after co-culture with a high glucose concentration implying that inhibition would be operative also under diabetic conditions.

In summary, fatty acids time-dependently inhibit glucoseinduced insulin secretion and biosynthesis. The specificity of this effect, its linkage to fatty acid oxidation indicate that a glucose-fatty acid cycle is operative in the pancreatic B cells. Elevated FFA in the starved and diabetic state potentially participate in the evolution or persistence of B cell insensitivity.

\section{Acknowledgments}

This work was supported by the Swedish Medical Research Council (Grant 04540), the Swedish Diabetes Association, the Magnus Bergvall Foundation, the Hoechst Diabetes Foundation, the Novo-Nordic Insulin Foundation, and funds from the Karolinska Institute.

\section{References}

1. Malaisse, W. J., L. Best, S. Kawazu, F. Malaisse-Lagae, and A. Sener. 1983. The stimulus-secretion coupling of glucose-induced insulin release: fuel metabo- lism in islets deprived of exogenous nutrients. Arch. Biochem. Biophys. 224:102110.

2. Crespin, S. R., W. B. Greenough, and D. Steinberg. 1973. Stimulation of insulin secretion by long-chain free fatty acids. J. Clin. Invest. 53:1979-1984.

3. Malaisse, W. J., and F. Malaisse-Lagae. 1968. Stimulation of insulin secretion by non-carbohydrate metabolites. J. Lab. Clin. Med. 72:438-448.

4. Randle, P. J., P. B. Garland, C. N. Hales, and E. A. Newsholme. 1963. The glucose fatty acid cycle, its role in insulin sensitivity and the metabolic disturbances in diabetes mellitus. Lancet i:785-789.

5. Randle, P. J., A. L. Kerbey, and J. Espinal. 1988. Mechanisms decreasing glucose oxidation in diabetes and starvation: role of lipid fuels and hormones. Diabetes Metab. Rev. 4:623-638.

6. Berne, C. 1975. The oxidation of fatty acids and ketone bodies in mouse pancreatic islets. Biochem. J. 152:661-666.

7. Malaisse, W. J., F. Malaisse-Lagae, A. Sener, and C. Hellerstrom. 1985. Participation of endogenous fatty acids in the secretory activity of the pancreatic B-cells. Biochem. J. 227:995-1002.

8. Prentki, M., S. Vischer, M. G. Glennon, R. Regazzi, J. T. Deeney, and B. E. Corkey. 1992. Malonyl-CoA and long chain Acyl-CoA esters as metabolic coupling factors in nutrient-induced insulin secretion. J. Biol. Chem. 267:58025810 .

9. Sako, Y., and V. Grill. 1990. A 48-hour lipid infusion in the rat time-dependently inhibits glucose-induced insulin secretion and B-cell oxidation through a process likely coupled to fatty acid oxidation. Endocrinology. 127:1580-1589.

10. Ferrannini, E., E. J. Barrett, S. Bevilacqua, and R. A. De Fronzo. 1983. Effect of fatty acids on glucose production and utilization in man. J. Clin. Invest. 72:1737-1747.

11. MacGarry, J. D. 1992. What if Minkowski had been ageusic? an alternative angle on diabetes. Science (Wash. DC). 258:766-770.

12. Lacy, P. E., and M. Kostianovsky. 1967. Method for the isolation of intact islets of Langerhans from the rat pancreas. Diabetes. 16:35-39.

13. Umbeit, W. W., R. H. Burris, and J. F. Stauffer. 1957. Manometric Techniques. Burgess Publishing Co., Minneapolis, MN. 149-150.

14. Halban, P. A., C. B. Wollheim, B. Blondel, and A. E. Renold. 1980. Long-term exposure of isolated pancreatic islets to mannoheptulose: evidence for insulin degradation in the cell. Biochem. Pharmacol. 29:2625-2633.

15. Keen, H., J. B. Field, and I. H. Pastan. 1963. A simple method for in vitro metabolic studies using small volumes of tissue and medium. Metab. Clin. Exp. 12:143-147.

16. Sener, A., and W. J. Malaisse. 1987. Stimulation by D-glucose of mitochondrial oxidative events in islet cells. Biochem. J. 246:89-95.

17. Herbert, V., K. S. Lau, C. W. Gottlieb, and S. J. Bleicher. 1965. Coated charcoal immunoassay of insulin. J. Clin. Endocrinol. Metab. 25:1375-1384.

18. Grill, V., M. Rundfeldt, and S. Efendic. 1981. Previous exposure to glucose enhances somatostatin secretion from the isolated perfused rat pancreas. Diabetologia. 30:495-500.

19. Wolf, H. P. O., K. Eistetter, and G. Ludwig. 1982. Phenylalkyloxirane carboxylic acids, a new class of hypoglycaemic substances: hypoglycaemic and hypoketonaemic effects of sodium 2-[5-(4-chlorophenyl)-pentyl-oxirane-2-carboxylate (B-807-27) in fasted animals. Diabetologia. 22:456-463.

20. Declercq, P. E., J. R. Falck, M. Kuwajima, H. Tyminski, D. W. Foster, and J. D. McGarry. 1987. Characterization of the mitochondrial carnitine palmitoyl-transferase enzyme system. Use of inhibitors. J. Biol. Chem. 262:98129821.

21. Foley, J. E. 1992. Rationale and application of fatty acid oxidation inhibitors in treatment of diabettes mellitus. Diabetes Care. 15:773-784.

22. Campillo, J. E., M. M. Valdivia, E. Rodriguez, and C. Osorio. 1979. Effect of oleic acid and octanoic acid on glucose-induced insulin release in vitro. Diabète Metab. 5:183-187.

23. Goberna, R., J. Jr Tamarit, R. Fussgänger, J. Tamarit, and E. F. Pfeiffer. 1974. Action of -hydroxybutyrate, acetoacetate and palmitate on the insulin release from the perfused isolated rat pancreas. Horm. Metab. Res. 6:256-260.

24. Malaisse, W. J. 1984. Insulin release: the fuel concept. Diabètes Metab. 9:313-320.

25. Meglasson, M. D., and F. M. Matschinsky. 1986. Pancreatic islet glucose metabolism and regulation of insulin secretion. Diabetes Metab. Rev. 2:163-214.

26. Tamarit-Rodriguez, J., E. Vara, J. Tamarit. 1984. Starvation-induced changes of palmitate metabolism and insulin secretion in isolated rat islets stimulated by glucose. Biochem. J. 221:317-324.

27. Capito, K., S. E. Hansen, C. J. Hedeskov, and P. Thams. 1992. Fat-induced changes in mouse pancreatic islet insulin secretion, insulin biosynthesis and glucose metabolism. Acta Diabetol. 28:193-198.

28. Bliss, C. R., and G. W. G. Sharp. 1992. Glucose-induced insulin release in islets of young rat: time-dependent potentiation and effect of 2-bromostearate. Am. J. Physiol. 263(Endocrinol. Metab. 26):E890-E896. 